\title{
Trabalhadores de saúde no Brasil: problemas e desafios no enfrentamento da COVID-19
}

Carmen F. Teixeira, ${ }^{1}$ Catharina M. Soares, ${ }^{2}$ Ednir Assis Souza,$^{3}$ Erick S. Lisboa, ${ }^{4}$ Isabela C.M. Pinto, ${ }^{5}$ Laise R. Andrade, ${ }^{6}$ Monique A. Esperidião ${ }^{7}$

1 Doutora em Saúde Pública pelo Instituto de Saúde Coletiva (ISC) da Universidade Federal da Bahia (UFBA). Professora títular aposentada do Instituto de Humanidades, Artes e Ciências (IHAC) da UFBA. Docente do Programa de Pós-Graduação em Saúde Coletiva (PPGSC) do ISC da UFBA.

2 Professora adjunta do Instituto de Saúde Coletiva (ISC) da Universidade Federal da Bahia (UFBA). Odontóloga, doutora em Saúde Pública e mestre em Saúde Comunitária pelo ISC da UFBA. Especialista em docência pela Escola Nacional de Saúde Pública (ENSP) da Fundação Oswaldo Cruz (Fiocruz). Pesquisadora do Observatório de Análise Política em Saúde.

3 Doutora em Saúde Pública, mestre em Enfermagem, especialista em Gestão de Sistemas de Saúde. Docente da Escola de Enfermagem da Universidade Federal da Bahia (UFBA). Membro do Grupo de Estudos Trabalho, Educação e Gestão em Saúde (GETEGS) do Instituto de Saúde Coletiva (ISC) da UFBA.

4 Farmacêutico pela Universidade Federal da Bahia (UFBA), mestre em Saúde Coletiva pelo Instituto de Saúde Coletiva (ISC) da UFBA, doutorando em Saúde Pública pelo ISC da UFBA e pesquisador do Programa de Economia e Tecnologia e Inovação em Saúde (PECS) do ISC.

5 Professora associada do Instituto de Saúde Coletiva (ISC) da Universidade Federal da Bahia (UFBA), doutora em Administração Pública, mestre em Saúde Coletiva. Coordenadora do Observatório de Análise Política em Saúde e do Grupo de Pesquisa Trabalho, Educação e Gestão em Saúde do ISC.

6 Psicóloga pela Universidade Federal da Bahia (UFBA), especialista em Medicina de Família e Comunidade pelo Instituto de Saúde Coletiva (ISC) da Universidade Federal da Bahia (UFBA), mestre em Gestão do Trabalho e Educação na Saúde pela Escola Nacional de Saúde Pública (ENSP) da Fundação Oswaldo Cruz (Fiocruz), doutora em Saúde Pública pelo ISC da UFBA; professora adjunta do ISC da UFBA.

7 Psicóloga, doutora em Saúde Pública pelo Instituto de Saúde Coletiva (ISC) da Universidade Federal da Bahia (UFBA) com estágio no Centro de Sociologia Europeia (CSE) da École des Hautes Études en Sciences Sociales (EHESS). Professora do ISC da UFBA. Tem experiência na área de políticas de saúde e avaliação em saúde.

TEIXEIRA, C. F.; SOARES, C. M.; SOUZA, E. A.; LISBOA, E. S.; PINTO, I. C. M.; ANDRADE, L.; ESPERIDIÃO, M. Trabalhadores de saúde no Brasil: problemas e desafios no enfrentamento da COVID-19. In: BARRETO, M. L.; PINTO JUNIOR, E. P.; ARAGÃO, E.; BARRAL-NETTO, M. (org.). Construção de conhecimento no curso da pandemia de COVID-19: aspectos biomédicos, clínico-assistenciais, epidemiológicos e sociais. Salvador: Edufba, 2020. v. 2. DOI: https://doi.org/10.9771/9786556300757.021 


\section{Introdução}

Os profissionais e trabalhadores de saúde constituem um grupo de risco para a COVID-19, principalmente os que se encontram na linha de frente do combate à pandemia, por estarem expostos diretamente aos pacientes infectados, o que faz com que recebam uma alta carga viral - milhões de partículas de vírus. Além disso, estão submetidos a enorme estresse ao atender esses pacientes, muitos em situação grave, em condições de trabalho, frequentemente, inadequadas, o que gera, além dos riscos de contaminação, sofrimento psíquico e diversos problemas de saúde mental.

Considerando que a força de trabalho em saúde não é homogênea porquanto apresenta diferenças de gênero, raça e classe social, que definem o acesso aos diversos níveis e cursos de formação profissional, e as oportunidades e formas de inserção no mercado de trabalho, é importante reconhecer que as condições e relações de trabalho, no âmbito dos serviços de saúde, conformam e reforçam diferentes graus de vulnerabilidade ao risco de adoecer e morrer por COVID-19. (BIROLI, 2016; HIRATA, 2005; HANKIVSKY, 2020)

De fato, os profissionais e trabalhadores de saúde envolvidos direta e indiretamente no enfrentamento 
da pandemia estão expostos cotidianamente ao risco de adoecer pelo novo coronavírus, sendo que a heterogeneidade que caracteriza esse contingente da força de trabalho determina formas diferentes de exposição, tanto ao risco de contaminação quanto aos fatores associados às condições de trabalho. Problemas como cansaço físico e estresse psicológico, insuficiência e/ou negligência com relação às medidas de proteção e cuidado à saúde desses profissionais, ademais, não afetam da mesma maneira as diversas categorias, sendo necessário atentar para as especificidades de cada categoria, de modo a evitar a redução da capacidade de trabalho e da qualidade da atenção prestada aos pacientes.

A proteção da saúde dos profissionais de saúde, assim, é fundamental para evitar transmissão do SARS-CoV-2 nos estabelecimentos de saúde e nos domicílios dos mesmos, sendo necessário adotar protocolos de controle de infecções - padrão, contato, via aérea - e disponibilizar Equipamentos de Proteção Individual (EPIs), incluindo máscaras N95, aventais, óculos, protetores faciais e luvas. Além disso, deve-se proteger a saúde mental dos profissionais e trabalhadores de saúde, por conta do estresse a que estão submetidos nesse contexto.

Por conta disso, essa questão, qual seja, as condições de trabalho e saúde dos profissionais de saúde foi objeto de revisão acelerada de artigos publicados em revistas internacionais, e nacionais utilizando o descritor "COVID" e variações. O produto desse trabalho foi publicado como Boletim $\mathrm{n}^{\circ} 5$ da Rede CoVida - Ciência, Informação e Solidariedade, ${ }^{8}$ que expõe a análise de cerca de 120 estudos, entre editoriais, cartas ao editor e artigos científicos, contendo informações sobre os principais problemas de saúde correlacionados com a pandemia da COVID-19 entre os profissionais e trabalhadores de saúde e as propostas, ações e estratégias adotadas para a promoção, proteção

8 Disponível em: https://covid19br.org/. 
e assistência à saúde dos profissionais de saúde que estão na linha de frente do combate à pandemia.

Paralelamente, foi feita uma revisão de artigos e documentos publicados por entidades representativas dos trabalhadores que estão realizando ações de vigilância e monitoramento dos efeitos da pandemia em hospitais e outros serviços de saúde, e acrescentou-se a análise dos boletins epidemiológicos da Secretaria de Vigilância em Saúde (SVS) do Ministério da Saúde. ${ }^{9}$ Foram incluídos apenas os boletins que tratavam da contaminação dos trabalhadores pelo novo coronavírus, notadamente as edições de número 22 ao 30 , sendo que os dados foram tabulados e processados de modo a apresentar o panorama da contaminação dos profissionais de saúde no Brasil.

Os resultados desse trabalho são apresentados a seguir, contemplando, inicialmente, uma síntese dos problemas de saúde física e mental - identificados na literatura internacional sobre a saúde dos trabalhadores de saúde no contexto da pandemia, seguida de uma descrição geral das condições de trabalho dos profissionais e trabalhadores de saúde brasileiros no período anterior à eclosão da pandemia, cenário no qual emergiram os problemas de saúde dos trabalhadores do Sistema Único de Saúde (SUS) relacionados ao enfrentamento da pandemia. Por fim, apresentamos e discutimos as medidas e estratégias que devem ser adotadas para prevenir e/ou mitigar os efeitos das atuais condições de trabalho no SUS face à pandemia da COVID-19.

9 Disponível em: https://www.saude.gov.br/boletins-epidemiologicos. 


\section{Impacto da pandemia na saúde dos trabalhadores de saúde: evidências na literatura}

Teixeira e demais autores (2020) apontam que o principal problema de saúde que afeta os profissionais de saúde envolvidos diretamente no cuidado aos pacientes sintomáticos ou diagnosticados com a infeç̧ão provocada pela COVID-19 é o risco de contaminação pela doença. Há muitas evidências que indicam o alto grau de exposição e contaminação dos profissionais de saúde pela COVID-19. (ANELLI, 2020; KOH, 2020; RAN et al., 2020; WANG; ZHOU; LIU, 2020)

Há evidencias também de que as categorias profissionais são afetadas desigualmente, assim como a população em geral. Barsoum (2020) refere dados de relatório apresentado por Cook e demais autores, apontando que ocorreram 106 mortes entre o pessoal do Serviço Nacional de Saúde (NHS) do Reino Unido, dos quais 33\% enfermeiras, 25\% trabalhadores de assistência médica e $17 \%$ médicos. Ressalta que os médicos de raça negra, asiática e de minorias étnicas (BAME) falecidos representaram 94\% do total de mortes no Reino Unido, embora representem somente $44 \%$ da força de trabalho no setor. Acrescenta o autor que a tendência foi semelhante entre os enfermeiros, cujas mortes representaram $71 \%$ no mesmo grupo BAME, por COVID-19 embora representem $20 \%$ da força de trabalho em saúde.

Nienhaus e Hod (2020), analisando dados de relatórios arquivados acerca dos casos por infecções por SARS-CoV-2 e doenças COVID-19 entre trabalhadores de saúde na Alemanha, verificaram alto índice de contaminação entre assistentes sociais e outros trabalhadores de saúde no país. Mesmo assim, a categoria profissional mais acometida por casos são os enfermeiros, cerca de $63,9 \%$. No que tange à síndrome aguda, esta afeta mais médicos, 
apresentando, inclusive, maior taxa de mortalidade para trabalhadores infectados com SARS-CoV-2. Os mesmos autores analisaram a contaminação dos profissionais de saúde por COVID-19 na Malásia. Concluíram que a infecção relacionada ao trabalho de profissionais de saúde ocorreu principalmente quando COVID-19 não foi suspeitado em pacientes e nenhum EPI adequado foi usado.

Estudo comparativo realizado em países do sul da Ásia ${ }^{10}$ analisou as estratégias operacionais desenvolvidas por formuladores de políticas e profissionais de saúde. Buscando opiniões de médicos envolvidos do enfretamento da COVID-19, os autores apontaram que nos países examinados há déficit de testagem, acesso restrito a médicos e a serviços de saúde, e os profissionais lutam por EPI. (BANIK et al., 2020)

As evidências internacionais convergem para a compreensão de que a insuficiência de EPI, necessário à proteção dos profissionais e trabalhadores que lidam diretamente com os pacientes infectados é um problema grave enfrentado pelos profissionais de saúde. A rápida elevação da demanda por EPIs tem sido, em todos os países que enfrentaram a primeira onda da pandemia, um dos fenômenos mais ressaltados na literatura, o que gerou, inclusive uma corrida nos mercados internacionais por esses equipamentos, sendo que a insuficiência e mesmo falta em alguns países foi relatado como uma circunstância que aumentou o risco de infecção por profissionais de saúde. (WANG; ZHOU; LIU, 2020)

A ausência de condições de trabalho que permitam a segurança dos trabalhadores foi relatada por Ortiz e demais autores (2020) como determinante do clima organizacional no sistema de saúde argentino - público, privado e seguro saúde sindical. Em um estudo de corte transversal, com abordagem mista - quantitativa

10 Foram incluídos oito países da Ásia, a saber: Bangladesh, Butão, Índia, Ilhas Maldivas, Nepal, Paquistão, Afeganistão, Siri Lanka. 
e qualitativa -, os resultados mostraram que a inacessibilidade de recursos institucionais e o acesso a EPIs foram uma grande preocupação, requerendo o estabelecimento de estratégias institucionais para apoiar os profissionais de saúde.

Trabalho realizado por Pessa e demais autores (2020), tomando o Brasil como lócus do estudo, revela que desde o início da pandemia há preocupações com a falta de EPI para a segurança dos trabalhadores da saúde, além da ausência de recomendações federais específicas sobre a localização de casos entre profissionais de saúde, uma vez que estes são desproporcionalmente afetados pelo COVID-19. Acrescentam as diretrizes de segurança apresentadas pelo Conselho Federal de Medicina (CFM) que envolve a criação de uma plataforma on-line para que os profissionais relatem carências de recursos, como a falta de EPIs nos locais de trabalho, sejam públicos ou privados. Os resultados do trabalho apontam que os trabalhadores da linha de frente estão perigosamente mal equipados devido a décadas de pouco investimento no setor de saúde pública, acesso limitado a EPIs e falta de educação permanente.

Cabe ressaltar que existe um debate no âmbito dos organismos internacionais com relação ao uso de EPIs pelos profissionais de saúde. A Organização Mundial da Saúde (OMS) recomenda o uso de máscaras tradicionais para os profissionais responsáveis por procedimentos de rotina e de respiradores para o cuidado de pacientes com procedimentos que geram aerossóis. Em outra direção, o CDC nos Estados Unidos e o Centro Europeu de Prevenção e Controlo das Doenças (ECDC) na Europa defendem o uso de respiradores em ambos os procedimentos, tanto os de rotina quanto aqueles de alto risco. Embora destaquem a importância do princípio da precaução, essas recomendações esbarram nas condições objetivas de disponibilidade desses EPIs para a proteção dos profissionais de saúde que trabalham na linha de frente. (CHUGHTAI et al., 2020) 
É importante destacar os efeitos adversos do uso de EPIs necessários para se evitar ou minimizar os riscos de infecção pela COVID-19. Um estudo (KOH, 2020) aponta a alta incidência de complicações cutâneas relacionadas a medidas de prevenção entre profissionais de saúde que tratam pacientes com infecção epidêmica por COVID-19, o que pode levar o profissional a não continuar usando equipamento de proteção devido a lesões cutâneas que afetam a ponte nasal, mãos, bochecha e testa. Ademais, a frequente higiene das mãos foi associada a uma maior incidência de dermatite nessa região. Outro estudo, realizado na China, aponta a propensão de lesões na pele e mucosa, proveniente do uso inadequado dos EPI na prevenção e controle da COVID 19, chamando a atenção para que os profissionais de saúde podem desenvolver dermatite aguda ou crônica, infecções secundárias e outras doenças de pele. Nesse caso, os especialistas chineses recomendam que os profissionais de saúde sigam, à risca, os padrões de uso do EPI e as especificações de esterilização e limpeza para evitar a ocorrência de efeitos adversos. (YAN et al., 2020)

\section{Impacto da pandemia na saúde mental dos trabalhadores de saúde: evidências na literatura}

Além dos riscos de contaminação, a pandemia tem gerado problemas de saúde mental que afetam particularmente os profissionais e trabalhadores de saúde, sendo recorrente o relato de aumento dos sintomas de ansiedade, depressão, perda da qualidade do sono, aumento do uso de drogas, sintomas psicossomáticos e medo de se infectarem ou transmitirem a infecção aos membros da família. (FIOCRUZ, 2020) 
Assim, a enorme pressão que esses trabalhadores enfrentam no seu cotidiano de trabalho, incluindo alto risco de infecção e proteção inadequada contra contaminação, excesso de trabalho, frustração, discriminação, isolamento, assistência a pacientes com emoções negativas, falta de contato com a família e exaustão tem causado problemas de saúde mental, como estresse, ansiedade, sintomas depressivos, insônia, negação, raiva e medo, problemas que não apenas afetam a atenção, o entendimento e a capacidade de tomada de decisões dos profissionais, mas também podem ter um efeito duradouro em seu bem-estar geral.

O medo de ser infectado, a proximidade com o sofrimento dos pacientes ou a morte desses, bem como a angústia dos familiares associada à falta de suprimentos médicos, informações incertas sobre vários recursos, solidão e preocupações com entes queridos foram aspectos também relatados em outro trabalho que abordou o sofrimento psíquico e o adoecimento mental dos profissionais de saúde, levando, em alguns casos, a relutância em trabalhar. (HUANG et al., 2020)

Além do transtorno de ansiedade generalizado, verificou-se o estresse crônico, exaustão ou esgotamento dos trabalhadores frente à intensa carga de trabalho, tendência que tende a piorar num contexto de carência de mão de obra na eventualidade dos profissionais de saúde terem que se isolar devido ao fato de contraírem a COVID-19. Além disso, alguns trabalhos chamam a atenção para o sentimento de impotência diante da gravidade e complexidade dos casos face à falta de leitos ou equipamentos de suporte à vida.

É importante destacar também a diferença do acometimento desses problemas quando se compara equipe com diferentes atividades na unidade hospitalar. Um estudo transversal realizado através de pesquisa on-line realizada na China, em abril, com 2.182 sujeitos teve como objetivo comparar o nível de problemas psicossociais 
de 927 profissionais de saúde - desses 680 eram médicos e 247 enfermeiros - com 1.255 profissionais de saúde não médicos durante o surto de COVID-19. Os quesitos investigados para os dois grupos foram prevalência de insônia, ansiedade, depressão, somatização e sintomas obsessivo-compulsivos. Em todos os quesitos investigados, os profissionais de saúde apresentaram escores totais mais elevados, conforme tabela síntese a seguir. (ZHANG et al., 2020)

Tabela 1 - Prevalência de problemas psicossociais em profissionais de saúde no contexto da pandemia da COVID-19

\begin{tabular}{l|c|c}
\multicolumn{1}{c|}{$\begin{array}{c}\text { Prevalência dos problemas } \\
\text { psicossociais }\end{array}$} & $\begin{array}{c}\text { Profissionais de } \\
\text { saúde }\end{array}$ & $\begin{array}{c}\text { Profissionais de saúde } \\
\text { não médicos }\end{array}$ \\
\hline Insônia & $38,4 \%$ & $30,5 \%$ \\
\hline Ansiedade & 13,0 & $8,5 \%$ \\
\hline Depressão & $12,2 \%$ & $9,5 \%$ \\
\hline Somatização & $1,6 \%$ & $0,4 \%$ \\
\hline $\begin{array}{l}\text { Sintomas } \\
\text { obsessivo-compulsivos }\end{array}$ & $5,3 \%$ & $2,2 \%$ \\
\hline
\end{tabular}

Fonte: elaborada pelos autores com base em Zhang e demais autores (2020).

Outro estudo, realizado em junho desse ano por Lu e demais autores (2020), por meio de questionários on-line a 2.200 participantes, ratifica esses achados, diferenciando o acometimento de transtornos mentais em equipes assistenciais $(n=2042)$ e administrativa ( $\mathrm{n}=257)$, no Hospital Provincial de Fujian, na China. A ocorrência de medo, ansiedade e depressão foram medidas pela Escala de Classificação Numérica (NRS) sobre o medo, a Hamilton Anxiety Scale (HAMA) e a Hamilton Depression Scale (HAMD), respectivamente. A equipe médica da linha de frente com contato próximo com pacientes infectados, trabalhando nos departamentos de doenças 
respiratórias, de emergência, infecciosas e Unidade de Terapia Intensiva (UTI), apresentou pontuações mais altas na escala de medo, sendo 1,4 vezes mais propensa a sentir medo e duas vezes mais propensos a sofrer ansiedade e depressão.

Além de concluir que a equipe médica que trabalhava nos departamentos anteriormente mencionados esteve suscetível a distúrbios psicológicos, Lu e demais autores (2020) acrescentaram que a carga de trabalho mais pesada e o risco de vida a que estavam expostos os profissionais médicos e os enfermeiros agravaram a pressão psicológica, com potencial desencadeamento de doença mental.

Uma síntese dos problemas mentais enfrentados pelos trabalhadores de saúde no contexto da pandemia foi feita por Ayanian (2020), que aponta os fatores que estão contribuindo para o sofrimento psicológico de enfermeiros, médicos, terapeutas respiratórios, auxiliares e outros profissionais de saúde que prestam atendimento direto a pacientes com COVID-19, quais sejam:

1. Esforço emocional e exaustão física ao cuidar de um número crescente de pacientes com doenças agudas de todas as idades que têm o potencial de se deteriorar rapidamente;

2. Cuidar de colegas de trabalho que podem ficar gravemente doentes e, às vezes, morrer de COVID-19;

3. Escassez de equipamentos de proteção individual que intensificam o medo de exposição ao coronavírus no trabalho, causando doenças graves;

4. Preocupações em infectar membros da família, especialmente membros da família mais velhos, imunocomprometidos ou com doenças crônicas;

5. Escassez de ventiladores e outros equipamentos médicos cruciais para o atendimento dos pacientes graves; 
6. Ansiedade em assumir papéis clínicos novos ou desconhecidos e cargas de trabalho expandidas no atendimento a pacientes com COVID-19;

7. Acesso limitado a serviços de saúde mental para gerenciar depressão, ansiedade e sofrimento psicológico.

Cabe enfatizar que, em vários dos estudos revisados, aparece a menção ao fato de que o grupo que mais sofre é composto por mulheres, enfermeiras, e profissionais de saúde envolvidos no diagnóstico, tratamento ou prestação de cuidados de enfermagem a pacientes com suspeita ou confirmação de COVID-19.

\section{Situação da força de trabalho em saúde no Brasil no período pré-pandemia}

A análise da situação da força de trabalho em saúde no Brasil tem sido feita em vários estudos - como por exemplo o de Machado e Ximenes Neto (2018) -, que apontam os principais problemas, tanto o que diz respeito à disponibilidade e distribuição das diversas categorias profissionais para atender às necessidades de funcionamento adequado dos serviços, nos diversos níveis de atenção, quanto os problemas relacionados à gestão do trabalho, isto é, aos mecanismos de contratação, qualificação e valorização da força de trabalho no setor.

Em 2018, a comissão de Gestão do trabalho e Educação na Saúde da Associação Brasileira de Saúde Coletiva (Abrasco) sistematizou, em publicação, o conjunto desses problemas (PINTO; PADILHA; NUNES, 2018), evidenciando as tendências configuradas ao longo dos anos, chamando a atenção para a necessidade de uma política de desenvolvimento de recursos humanos em saúde que valorize o planejamento, a regulação das relações de trabalho, a educação permanente dos profissionais e trabalhadores do setor, 
na contramão do que vem se observando no cotidiano da gestão do SUS ao nível federal, estadual e municipal.

Ao tempo em que apontam os problemas decorrentes do subfinanciamento do SUS, do congelamento dos gastos no setor, da deterioração dos serviços e da precarização da força de trabalho, esses estudos denunciam os efeitos negativos de tais problemas na prestação de serviços de atenção, particularmente na atenção primária, seriamente afetada pelas mudanças na lógica do financiamento ocorrida nos últimos anos. Configura-se, de fato, uma crise permanente do sistema de saúde, fortemente afetada pela reorientação das políticas de saúde adotadas a partir da crise econômica e do "golpe do capital" (TEIXEIRA; PAIM, 2018) na saúde, marcadas pela financeirização da saúde, pelo ajuste fiscal - Emenda Constitucional $\mathrm{n}^{\circ} 95$-, restauração do neoliberalismo, privatização "por dentro" do sistema público e desmonte do SUS tal como foi proposto e legitimado na Constituição Federal de 1988.

O "SUS real", com seus problemas crônicos, é o cenário em que se coloca o desafio do enfrentamento e controle da pandemia da COVID-19 no Brasil, até porque o sistema privado, de assistência médica supletiva, cobre apenas cerca de $1 / 4$ da população brasileira, basicamente com assistência médico-hospitalar, o que traz um problema adicional ao atendimento dos casos, na medida em que esse sistema dispõe de mais de 2/3 dos leitos hospitalares no país.

Tal cenário complica-se no contexto do enfrentamento da pandemia da COVID-19 no Brasil. As evidências internacionais apontam que a mesma demanda um esforço conjunto das autoridades políticas, dos organismos internacionais, da sociedade civil, de todos os sujeitos para o seu controle (TANNE et al., 2020; THE WORLD..., 2020), pois trata-se de um desafio global. (WERNECK, 2020) No Brasil, ademais, somam-se um conjunto de fatores de ordem política e ideológica (THE LANCET, 2020) que influenciam nas dificuldades de estruturação do SUS para o enfrentamento da emergência sanitária 
no país, envolvendo a infraestrutura física das unidades de saúde, oferta de materiais e equipamentos, disponibilização de profissionais de saúde treinados e devidamente protegidos para o desenvolvimento das suas ações.

\section{O Impacto da pandemia de COVID-19 na saúde dos trabalhadores do SUS}

A extrema desigualdade social que caracteriza a situação brasileira potencializa os riscos de disseminação e contaminação das populações de baixa-renda que vivem em condições precárias nas periferias das grandes cidades brasileiras, cujos efeitos sobre as taxas de morbidade e letalidade já estão sendo anunciadas por vários pesquisadores que apontam a tragédia anunciada da pandemia de COVID-19 no país.

Nesse contexto, o SUS, que atinge uma cobertura de cerca de $75 \%$ da população, constitui o maior recurso de que se dispõe para o enfrentamento dessa situação. Cabe, entretanto, ressaltar os desafios enfrentados por esse sistema durante seus 30 anos de existência, expressos no subfinanciamento, na articulação público-privada, nos limites da gestão político-institucional, nas dificuldades de organização da prestação de serviços tendo em vista a integralidade do cuidado, e, também, na insuficiência relativa e na desqualificação e desvalorização dos trabalhadores de saúde. (TEIXEIRA; PAIM, 2018)

Apesar de todos estes problemas, o SUS e, especialmente, os aproximadamente 3,5 milhões de profissionais e trabalhadores de saúde que continuam atuando em cerca de 5 mil hospitais e centenas de milhares de unidades básicas de saúde espalhadas nos 5700 municípios do país, constituem a chamada "linha de frente" do enfrentamento da pandemia. 
Diante da insuficiência de infraestrutura, principalmente de leitos hospitalares, UTI e equipamentos de respiração mecânica (respiradores) no SUS, foi agilizada a implementação dos hospitais de campanha, estratégia que traz consigo a necessidade imediata de contratação de pessoal, o que vem sendo feito através da reprodução em larga escala dos vínculos precários, terceirizados, sem garantias trabalhistas, representando o que vem sendo denominado de "uberização" da força de trabalho em saúde.

Além disso, ou seja, da contratação acelerada de profissionais que estavam desempregados - especialmente pessoal de enfermagem - ou atuando como autônomos, tratou-se de acelerar a conclusão dos cursos e fornecimento de diplomas a estudantes de Medicina e outras profissões de saúde, para preencher as novas vagas criadas pela expansão dos serviços.

Tais medidas emergenciais, embora necessárias, geram novos problemas, decorrentes do desconhecimento das regras institucionais e inexperiência dos profissionais contratados acerca dos procedimentos a serem adotados no enfrentamento da pandemia, o que demanda um esforço redobrado em termos de capacitação e educação permanente desses profissionais.

Expostos cotidianamente ao risco de contaminação, submetidos a condições de trabalho precarizadas, e estressados face à sobrecarga de trabalho e dramaticidade do sofrimento e morte dos pacientes e angústia de seus familiares, o enorme contingente de profissionais e trabalhadores de saúde envolvidos no combate à COVID-19, incluindo pessoal de serviços gerais, maqueiros, pessoal de limpeza, transporte e alimentação etc. constituem, ao nosso ver, o nó crítico a ser desatado para se garantir um mínimo de eficiência e efetividade no enfrentamento da pandemia em nosso país.

Levantamentos feitos por associações profissionais, notadamente as ligadas à enfermagem, boletins epidemiológicos, notícias 
veiculadas pela mídia e reportagens feitas com profissionais de saúde que estão atuando diretamente em unidades hospitalares que atendem pacientes de COVID-19, dão conta da gravidade da situação vivenciada nos serviços de saúde. O risco de contaminação pela falta de EPI bem como a ansiedade provocada pelo uso desses equipamentos, em turnos de até 6 horas ininterruptas em UTIs, com uso de fraldas, além da ansiedade vivenciada no momento da desparamentação, isto é, da retirada desses equipamentos, tem provocado um intenso sofrimento nesses profissionais, levando, inclusive, ao afastamento do trabalho, o que compromete, ainda mais, a qualidade do atendimento prestado à população.

Segundo relatório do Conselho Federal de Enfermagem (Cofen), ${ }^{11}$ publicado no dia 19 de agosto, 16.577 profissionais de enfermagem foram acometidos pela COVID-19 no Brasil. Desses, 229 foram internados e 342 morreram pela doença, ${ }^{12}$ cifra maior do que as da Itália e da Espanha juntas, países que acumulam mais de 50 mil mortes, contra as 110 mil oficialmente registradas no Brasil.

Os casos suspeitos somam 14.248. A liderança em número de casos da COVID-19 confirmados entre as(os) trabalhadoras(es) de enfermagem, quando comparada aos demais trabalhadores da saúde, é reiterada no boletim epidemiológico publicado pelo Ministério da Saúde (BOLETIM EPIDEMIOLÓGICO ESPECIAL, 2020e), no qual a categoria de técnicos de enfermagem desponta em primeiro lugar, seguida de enfermeiros e de médicos.

11 Ver em: http://observatoriodaenfermagem.cofen.gov.br/.

12 Segundo o chefe do departamento de Gestão do Exercício Profissional do Cofen, isso é apenas a ponta do iceberg, uma vez "[...] que as ações de fiscalização do órgão alcançaram, até o momento, $27 \%$ do total de profissionais da área. Segundo ele, foram recebidas mais de 4.590 denúncias, boa parte delas referente [a] [...] EPIs para as equipes de enfermagem". (ALESSI, 2020) 
Segundo o Cofen (2020), as unidades federadas que apresentaram maior número de casos notificados da doença entre as(os) trabalhadoras(es) de enfermagem foram São Paulo (5.600 casos); Rio de Janeiro (4.466 casos); Bahia (3.951 casos) e Rio Grande do Sul (2.703 casos). Em relação aos óbitos por COVID-19, foram: São Paulo (63); Rio de Janeiro (45); Pernambuco (29), seguido por Mato Grosso (26).

Ao todo, segundo dados do Ministério da Saúde, até a $39^{\circ}$ semana epidemiológica, 288.936 trabalhadores de saúde brasileiros foram contaminados e 2.099 mortos em meio ao combate à pandemia do novo coronavírus. (ANELLI, 2020) Desses óbitos, aproximadamente, $52 \%$ são mulheres, que constituem, como se sabe, mais de $51 \%$ da força de trabalho no setor.

Somam-se, do início da epidemia no Brasil até 5 de setembro de 2020, segundo dados do Centro de Operações de Emergência (COE) do Ministério da Saúde, 10.632 .989 casos suspeitos de COVID-19, entre os trabalhadores da saúde. Desse quantitativo, $25 \%$, ou seja, 2.335 .788 casos foram confirmados, sendo importante destacar que as categorias mais acometidas são os técnicos e auxiliares de enfermagem, seguidos dos enfermeiros e médicos, na sequência, os Agentes Comunitários de Saúde (ACS) e recepcionistas de unidades de saúde (Tabela 2).

No que se refere à Síndrome Respiratória Aguda (SRAG), no mesmo período examinado, 15.895 profissionais de saúde registram internamento e, desse total, 9.503 foram confirmados por SRAG, indo a óbito 2.698 , cerca de $26 \%$ dos profissionais internados. Acrescenta-se que, segundo os boletins do COE, as categorias profissionais mais afetadas foram técnicos/auxiliares de enfermagem (33,0\%), médicos (20,0\%) e enfermeiros (13,0\%). (BOLETIM EPIDEMIOLÓGICO COVID-19, 2020a, 2020b) 
Tabela 2 - Situação de COVID-19 entre os profissionais de saúde no Brasil

\begin{tabular}{|c|c|c|c|c|c|}
\hline $\begin{array}{c}\text { Semana } \\
\text { Epidemiológica }\end{array}$ & $\begin{array}{l}\text { Casos suspeitos } \\
\text { de Síndrome } \\
\text { Respirátoria(SG) }\end{array}$ & $\begin{array}{c}\text { Casos confirmados } \\
\text { de Síndrome } \\
\text { Respirátoria(SG) }\end{array}$ & $\begin{array}{l}\text { Casos suspeitos } \\
\text { de Síndome } \\
\text { Respiratória } \\
\text { Aguda (SRAG) } \\
\text { hospitalizados }\end{array}$ & $\begin{array}{c}\text { Casos } \\
\text { confirmados } \\
\text { de Síndome } \\
\text { Respiratória } \\
\text { Aguda (SRAG) } \\
\text { hospitalizados }\end{array}$ & $\begin{array}{c}\text { Óbitos por } \\
\text { SRAG }\end{array}$ \\
\hline 27 & 786.417 & 173.440 & 1219 & 697 & 176 \\
\hline 28 & 866.068 & 180.028 & 1373 & 788 & 205 \\
\hline 29 & 944.238 & 195.516 & 1437 & 807 & 218 \\
\hline 30 & 1.023 .150 & 216.367 & 1522 & 860 & 232 \\
\hline 31 & 1.086 .807 & 232.992 & 1585 & 920 & 243 \\
\hline 32 & 1.116.197 & 243.342 & 1652 & 980 & 445 \\
\hline 33 & 1.169 .398 & 257.156 & 1694 & 1034 & 277 \\
\hline 34 & 1.212 .430 & 268.954 & 1.738 & 1.093 & 289 \\
\hline 35 & 1.250 .282 & 279.057 & 1749 & 1105 & 292 \\
\hline 36 & 1.178 .002 & 288.936 & 1926 & 1219 & 321 \\
\hline Total & 10.632 .989 & 2.335 .788 & 15895 & 9503 & 2698 \\
\hline
\end{tabular}

Fonte: elaborada pelos autores com base Boletim Epidemiológico Especial (2020a, 2020b, 2020c, 2020d, 2020e, 2020f, 2020g, 2020h, 2020i, 2020j).

\section{O impacto da pandemia da COVID-19 nos trabalhadores da saúde na Bahia}

Especificamente com relação ao estado da Bahia, a Secretaria Estadual de Saúde (Sesab) tem publicado, diariamente, através de boletins epidemiológicos, o número de casos de COVID-19 em trabalhadores da saúde no estado, desagregados por diversas categorias profissionais. Até o Boletim n ${ }^{\circ} 129$, de 31 de julho de 2020, foram registrados 15.137 casos acumulados de COVID-19 em profissionais de saúde. As categorias com maior número de casos são os técnicos 
e auxiliares de enfermagem com 4.789 (31,7\%) casos acumulados, enfermagem 2.746 (18,1\%), medicina com $1.402(9,3 \%)$ casos e ACS com 719 (4,7\%), podendo-se observar mais detalhes na Tabela 3. (BOLETIM EPIDEMIOLÓGICO COVID-19, 2020a)

Tabela 3 - Casos de COVID-19 por categorias profissionais no estado da Bahia, 2020

\begin{tabular}{|c|c|c|c|c|c|c|c|c|}
\hline \multirow{2}{*}{ Categorias } & \multicolumn{2}{|c|}{ Maio* } & \multicolumn{2}{|c|}{ Junho } & \multicolumn{2}{|c|}{ Julho } & \multicolumn{2}{|c|}{ Total } \\
\hline & $\mathbf{n}$ & $\%$ & $\mathbf{n}$ & $\%$ & $\mathbf{n}$ & $\%$ & $\mathbf{n}$ & $\%$ \\
\hline Tec/aux Enfermagem & 890 & 33 & 1.902 & 31,5 & 2.006 & 31,3 & 4.798 & 31,7 \\
\hline Enfermagem & 555 & 20,6 & 1.079 & 18 & 1.112 & 17,3 & 2.746 & 18,1 \\
\hline Medicina & 312 & 11,6 & 583 & 9,7 & 507 & 7,9 & 1.402 & 9,3 \\
\hline Assistente Social & 56 & 2 & 71 & 1,2 & 88 & 1,4 & 215 & 1,4 \\
\hline Fisioterapia & 96 & 3,6 & 149 & 2,5 & 211 & 3,3 & 456 & 3 \\
\hline Nutrição & 38 & 1,4 & 89 & 1,5 & 97 & 1,5 & 224 & 1,5 \\
\hline Farmácia & 35 & 1,3 & 104 & 1,7 & 114 & 1,8 & 253 & 1,7 \\
\hline ACS & 38 & 1,4 & 256 & 4,2 & 425 & 6,6 & 719 & 4,7 \\
\hline Odontologia & 24 & 0,9 & 97 & 1,6 & 123 & 1,9 & 244 & 1,6 \\
\hline Psicologia & 30 & 1,1 & 65 & 1 & 73 & 1,1 & 168 & 1,1 \\
\hline Ag. Combate Endemias & 14 & 0,5 & 114 & 1,9 & 153 & 2,4 & 281 & 1,9 \\
\hline Fonoaudiologia & 9 & 0,3 & 22 & 0,4 & 13 & 0,2 & 44 & 0,3 \\
\hline Biomedicina & 7 & 0,3 & 16 & 0,3 & 28 & 0,4 & 51 & 0,3 \\
\hline Outros & 596 & 22 & 1.477 & 24,5 & 1.463 & 22,9 & 3.536 & 23,4 \\
\hline Total & 2.700 & 100 & 6.024 & 100 & 6.413 & 100 & 15.137 & 100 \\
\hline $\begin{array}{l}\text { *O número de profission } \\
\text { também dos meses ante } \\
\text { Bahia começarem a ser }\end{array}$ & $\begin{array}{l}\text { s confirm } \\
\text { ores, dev } \\
\text { vulgados }\end{array}$ & $\begin{array}{l}\text { dos co } \\
\text { do aos } \\
\text { partir }\end{array}$ & $\begin{array}{l}\text { COVID-1 } \\
\text { dos com } \\
\text { boletim }\end{array}$ & $\begin{array}{l}\text { no mê } \\
\text { númer } \\
\text { idemi }\end{array}$ & $\begin{array}{l}\text { le maio } \\
\text { de caso } \\
\text { ógico d }\end{array}$ & $\begin{array}{l}\text { orrespo } \\
\text { dos pro } \\
9 \text { de } n\end{array}$ & $\begin{array}{l}\text { Je ao acur } \\
\text { sionais no } \\
\text { o de } 2020\end{array}$ & $\begin{array}{l}\text { lado } \\
\text { tado d }\end{array}$ \\
\hline
\end{tabular}

Fonte: elaborada pelos autores com base no Boletim Epidemiológico COVID-19 (2020a). 
Cabe destacar que o primeiro boletim epidemiológico da Sesab que traz esses números foi publicado em 9 de maio de 2020 - Boletim n $\mathrm{n}^{\circ} 45$ - trazendo, portanto, junto aos casos de maio o acumulado dos meses de março e abril. (BOLETIM EPIDEMIOLÓGICO COVID-19, 2020b) Percebe-se um crescimento do número de casos em todas as categorias de maio a julho, sendo uma variação maior no número de casos nas categorias de ACS e Agente de Combate a Endemias (ACE), seguidos dos farmacêuticos, odontólogos e biomédicos (Tabela 2). Chama atenção também o fato de que os casos em trabalhadores da saúde correspondem a 9,11\% do total de casos de COVID-19 do estado da Bahia, ou seja, a cada 100 casos de COVID-19 no estado, cerca de nove são trabalhadores da saúde (Tabela 4).

Tabela 4 - Proporção do número de profissionais com COVID-19, por categoria, no estado da Bahia e em relação ao total do estado, 2020

\begin{tabular}{l|c|c|c}
\multirow{2}{*}{\multicolumn{1}{c}{ Categorias }} & \multicolumn{2}{|c|}{$\begin{array}{c}\text { Profissionais positivos } \\
\text { CoVID-19, Bahia }\end{array}$} & $\begin{array}{c}\text { Proporção em relação ao total do } \\
\text { estado ( } \mathbf{n}=166.154 \text { casos) }\end{array}$ \\
\cline { 2 - 4 } Tec/aux Enfermagem & $\mathbf{n}$ & $\%$ & 2,89 \\
\hline Enfermagem & 4.798 & 31,7 & 1,65 \\
\hline Medicina & 2.746 & 18,1 & 0,84 \\
\hline Assistente Social & 21.402 & 9,3 & 0,13 \\
\hline Fisioterapia & 456 & 3,4 & 0,27 \\
\hline Nutrição & 224 & 1,5 & 0,13 \\
\hline Farmácia & 253 & 1,7 & 0,15 \\
\hline ACS & 719 & 4,7 & 0,43 \\
\hline Odontologia & 244 & 1,6 & 0,15 \\
\hline Psicologia & 168 & 1,1 & 0,1 \\
\hline Ag. Combate Endemias & 281 & 1,9 & 0,17 \\
\hline
\end{tabular}




\begin{tabular}{l|c|c|c}
\multirow{2}{*}{\multicolumn{1}{c|}{ Categorias }} & \multicolumn{2}{|c|}{$\begin{array}{c}\text { Profissionais positivos } \\
\text { CovID-19, Bahia }\end{array}$} & $\begin{array}{c}\text { Proporção em relação ao total do } \\
\text { estado ( } \mathbf{n}=166.154 \text { casos) }\end{array}$ \\
\cline { 2 - 4 } & $\mathbf{n}$ & $\%$ & $\%$ \\
\hline Fonoaudiologia & 44 & 0,3 & 0,03 \\
\hline Biomedicina & 51 & 0,3 & 0,03 \\
\hline Outros & 3.536 & 23,4 & 2,13 \\
\hline Total & $\mathbf{1 5 . 1 3 7}$ & $\mathbf{1 0 0}$ & $\mathbf{9 , 1 1}$ \\
\hline
\end{tabular}

Fonte: elaborada pelos autores com base no Boletim Epidemiológico COVID-19 (2020a).

Comparando os casos totais acumulados de trabalhadores da saúde na Bahia com os casos de trabalhadores no Brasil, encontra-se a proporção de 6,5\%, ou seja, a cada 100 trabalhadores da saúde contaminados com Sars-CoV-2 no Brasil, cerca de seis são da Bahia. Quando comparamos a Bahia em relação ao Brasil por categoria profissional, percebe-se que a maior proporção de trabalhadores da Bahia que testaram positivo para COVID-19 são assistentes sociais (9,3\%), ACEs (8,6\%), nutricionistas (8,3\%), fisioterapeutas (7,6\%), ACS e psicólogos com 6,3\% cada, conforme Tabela 5 .

Tabela 5 - Proporção do número de profissionais com COVID-19, por categoria, no estado da Bahia e no Brasil, 2020

\begin{tabular}{l|c|c|c|c|c}
\multirow{2}{*}{ Categorias } & \multicolumn{2}{|c|}{$\begin{array}{c}\text { Profissionais positivos } \\
\text { CoVID-19, Bahia }\end{array}$} & \multicolumn{2}{c|}{$\begin{array}{c}\text { Profissionais positivos } \\
\text { COVID-19, Brasil }\end{array}$} & $\begin{array}{c}\text { Proporção } \\
\text { Bahia/Brasil }\end{array}$ \\
\cline { 2 - 6 } & $\mathbf{n}$ & $\%$ & $\mathbf{n}$ & $\%$ & $\%$ \\
\hline Tec/aux Enfermagem & 4.798 & 31,7 & 80.287 & 34,3 & 6 \\
\hline Enfermagem & 2.746 & 18,1 & 34.196 & 14,6 & 8 \\
\hline Medicina & 1.402 & 9,3 & 25.402 & 10,9 & 5,5 \\
\hline Assistente Social & 215 & 1,4 & 2.312 & 1 & 9,3 \\
\hline Fisioterapia & 456 & 3 & 5.972 & 2,6 & 7,6 \\
\hline Nutrição & 224 & 1,5 & 2.682 & 1,2 & 8,3 \\
\hline Farmácia & 253 & 1,7 & 4.745 & 2 & 5,3 \\
\hline
\end{tabular}




\begin{tabular}{|c|c|c|c|c|c|}
\hline \multirow[t]{2}{*}{ Categorias } & \multicolumn{2}{|c|}{$\begin{array}{l}\text { Profissionais positivos } \\
\text { COVID-19, Bahia }\end{array}$} & \multicolumn{2}{|c|}{$\begin{array}{c}\text { Profissionais positivos } \\
\text { COVID-19, Brasil }\end{array}$} & \multirow{2}{*}{$\begin{array}{c}\begin{array}{c}\text { Proporção } \\
\text { Bahia/Brasil }\end{array} \\
\%\end{array}$} \\
\hline & $\mathbf{n}$ & $\%$ & $\mathbf{n}$ & $\%$ & \\
\hline ACS & 719 & 4,7 & 11.369 & 4,9 & 6,3 \\
\hline Odontologia & 244 & 1,6 & 4.387 & 1,9 & 5,6 \\
\hline Psicologia & 168 & 1,1 & 2.663 & 1,1 & 6,3 \\
\hline Ag. Combate Endemias & 281 & 1,9 & 3.277 & 1,4 & 8,6 \\
\hline Fonoaudiologia & 44 & 0,3 & 759 & 0,3 & 5,8 \\
\hline Biomedicina & 51 & 0,3 & 1.939 & 0,8 & 2,6 \\
\hline Outros & 3.536 & 23,4 & 53.804 & 23 & 6,6 \\
\hline Total & 15.137 & 100 & 233.794 & 100 & 6,5 \\
\hline
\end{tabular}

Fonte: elaborada pelos autores com base no Boletim Epidemiológico

Especial (2020e).

Para observarmos a tendência na evolução e na variação percentual de casos entre os profissionais de saúde no estado da Bahia, foram compostos dois grupos: o primeiro relativo às três categorias com maior número de casos - técnicos e auxiliares de enfermagem, enfermagem e medicina -; e o segundo, com as demais categorias que constam no boletim epidemiológico da Sesab (Figuras 1 e 2).

Na Figura 1, verifica-se a tendência no número de casos diários a partir de 9 de maio até 31 de julho de 2020. No grupo que agrega as três categorias com maior número de casos, os técnicos e auxiliares de enfermagem apresentam um crescimento mais agudo, mas as três categorias seguem uma tendência de crescimento relativamente constante (Figura 1A). Na Figura 1B, vê-se uma variação maior na tendência, sendo que a categoria dos fisioterapeutas apresentava, até meados de junho, um maior crescimento, e, a partir desse período, os ACS passaram a acumular mais casos diários de COVID-19. Os assistentes sociais, farmacêuticos, ACEs, nutricionistas e odontólogos seguem uma tendência 
intermediária em relação às duas primeiras, enquanto os psicólogos, fonoaudiólogos e biomédicos apresentam um menor crescimento diário, mais baixo, porém constante.

Figura 1 - Evolução temporal diária do número de casos de COVID-19 em profissionais de saúde no estado da Bahia, 2020

$1 \mathrm{~A}$

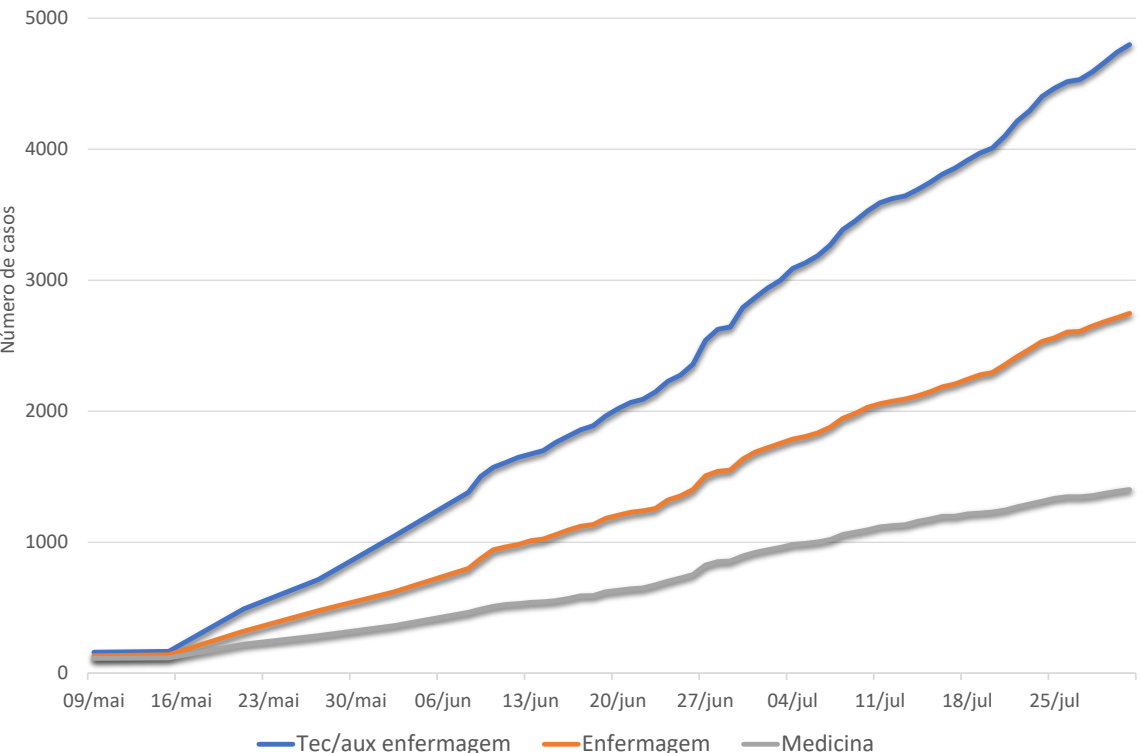




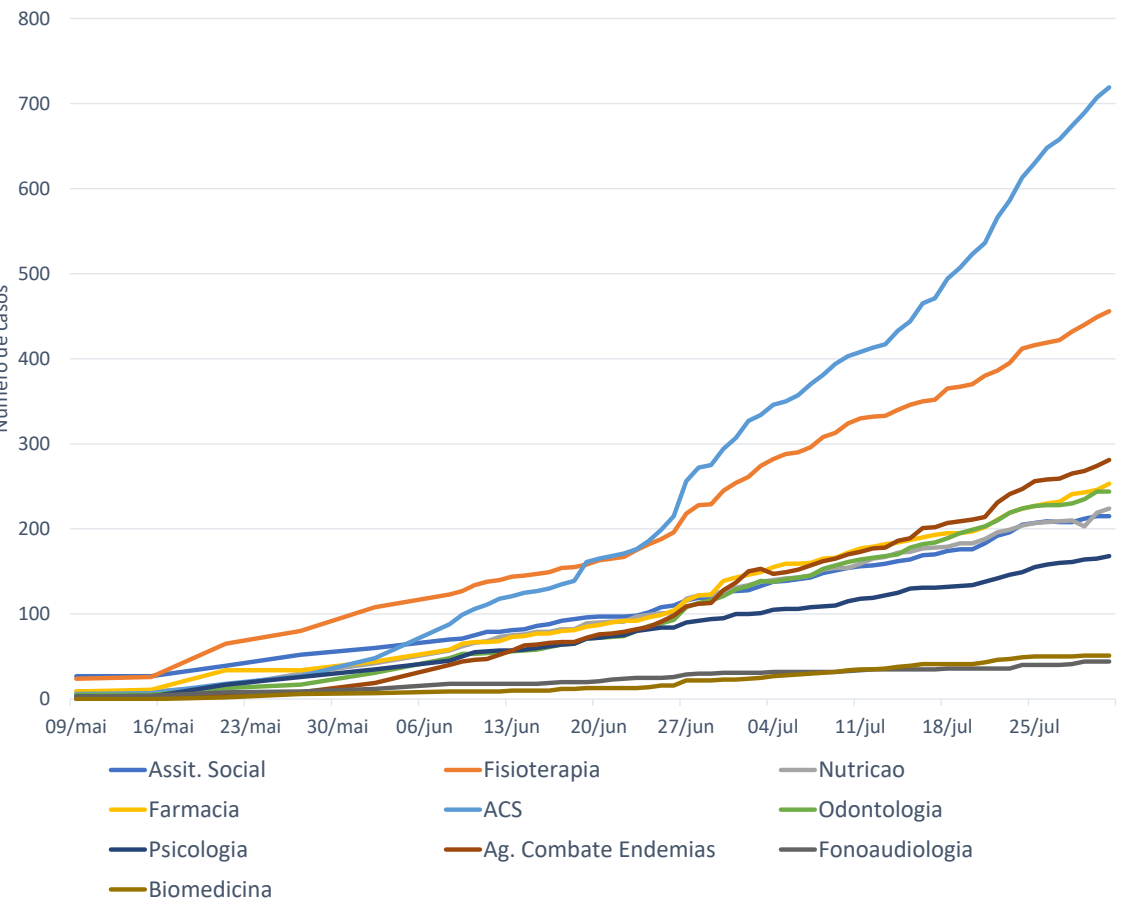

Fonte: elaborada pelos autores com base no Boletim Epidemiológico COVID-19 (2020a, 2020b).

A Figura 2 representa a variação percentual nos meses de maio, junho e julho de cada categoria em relação ao total de cada mês. Pode-se verificar que, em termos percentuais, há uma queda nas três categorias com maior número de casos, com uma variação maior para a categoria médica. Em contrapartida, nas demais categorias, em geral há um aumento percentual, com destaque para os ACS, Farmácia, Odontologia e ACEs (Figura 2B). Isso pode ser reflexo que algumas dessas atividades profissionais foram temporariamente reduzidas devido ao fechamento de alguns estabelecimentos de saúde que só foram reabertos a partir de meados de junho, a exemplo das clínicas odontológicas. 
Figura 2 - Variação percentual do número de casos de COVID-19 em profissionais de saúde no estado da Bahia nos meses de maio, junho e julho, 2020

$2 \mathrm{~A}$

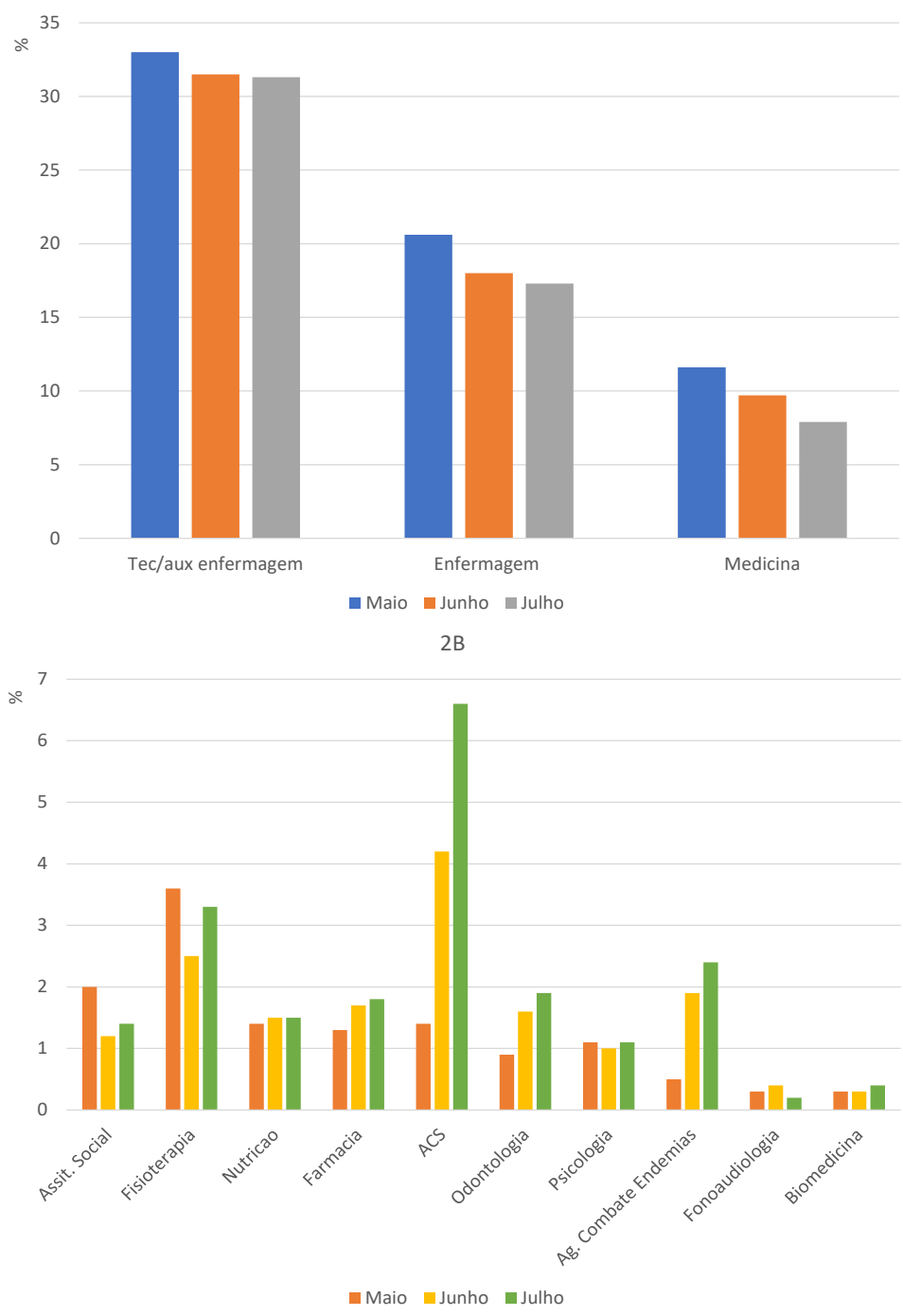

Fonte: elaborada pelos autores com base no Boletim Epidemiológico COVID-19 (2020a, 2020b). 
A Sesab publica, de forma separada dos boletins epidemiológicos do estado, o Boletim informativo da COVID-19 sobre as(os) trabalhadoras(es) da saúde. O último boletim, publicado no dia 17 de julho (BOLETIM INFORMATIVO COVID-19, 2020c), informa que o número de trabalhadoras(es) da Sesab que testou positivo para o coronavírus foi 4.545 , correspondendo a $37,6 \%$ dos casos totais de trabalhadoras(es) da saúde no estado da Bahia, que até aquela data totalizavam 12.097 casos.

Até esse mesmo boletim, as categorias de nível técnico e médio de trabalhadores vinculados à Sesab que tiveram as maiores proporções de positivos foram os maqueiros com 17,6\% (313 testados/55 positivos), porteiros com 15,4\% (13/2), técnicos/auxiliares de laboratórios/patologia com 14,9\% (538/80) e 14,2\% (9.769/1.387) para os técnicos e auxiliares de enfermagem, este que em números absolutos é a categoria com maior número de casos. Já em relação às mortes, o boletim (BOLETIM INFORMATIVO COVID-19, 2020c) mostra que 10 evoluíram a óbito, sendo: um auxiliar de regulação, um almoxarife, um enfermeiro, um auxiliar de enfermagem, um auxiliar administrativo, três médicos, um agente de saúde pública e uma enfermeira/diretora geral (Bahia).

Além do impacto sobre a saúde física dos trabalhadores de saúde por conta da contaminação pelo novo coronavírus, tem se observado grande impacto sobre a saúde mental, o que tem exigido, por parte da Sesab, a organização de ações de acolhimento suporte e atendimento a problemas dessa natureza. Embora não tenha sido realizada, até o momento, nenhuma pesquisa especifica sobre as formas de sofrimento psíquico provocadas pela inserção dos trabalhadores no contexto geral da pandemia e, especificamente, sobre os possíveis efeitos das condições de trabalho dos que estão diretamente na linha de frente de atendimento aos casos da COVID-19 nos diversos serviços de saúde, o surgimento de demandas específicas nessa área fez com que a Sesab implantasse, em julho de 
2020, o Centro de Acolhimento Psicológico Emergencial para Trabalhadores da Saúde no enfrentamento da COVID-19.

Esse centro tem ofertado um conjunto heterogêneo de cuidados em saúde mental aos trabalhadores da instituição, incluindo serviços de acolhimento, orientação, Primeiros Cuidados Psicológicos (PCP), plantão psiquiátrico e também desenvolvimento de Práticas Integrativas e Complementares de Saúde (PICS) à distância. O volume de atendimentos realizados até o momento dá uma ideia aproximada da magnitude do problema, uma vez que, em pouco mais de dois meses de funcionamento já foram realizados cerca de 1.190 atendimentos, sendo que desses, 894 (75,1\%) foram referenciados pelo Centro de Testagem e Atendimento e $266(22,4 \%)$ foram prestados para atendimento à demanda espontânea. (BOLETIM INFORMATIVO COVID-19, 2020c)

O atendimento psiquiátrico nesse centro é realizado por meio de recursos digitais e/ou contato telefônico. Demandas que impliquem cuidado presencial são encaminhadas para unidades parceiras da Sesab, assim como ao Serviço Integrado de Atenção à Saúde do Trabalhador (Siast) assistencial, ligada ao Programa de Atenção Integral à Saúde da Trabalhadora e do Trabalhador da SESAB (Paist).

O serviço mais acionado entre os trabalhadores tem sido o acolhimento pontual/ breve (772), que desenvolve ações de escuta e suporte emocional, bem como alívio de tensão e estresse. Em seguida, o atendimento psicológico aos profissionais (326), cuja oferta concentra-se em necessidades relacionadas a estafa, fobias, crise de ansiedade e outros. Há ainda o atendimento psiquiátrico (44) que se ocupa de demandas que exigem tratamento medicamentoso, muitas vezes, como ideação suicida e/ou transtornos mentais, propriamente ditos, como depressão, síndrome do pânico, estresse pós-traumático, ansiedade generalizada e outros transtornos e manifestações clínicas. Em menor número absoluto, 
foram realizados atendimentos para as práticas integrativas (21). (BOLETIM INFORMATIVO COVID-19, 2020c)

A categoria profissional que mais tem demandado o centro é a técnico/auxiliar de enfermagem, independente do serviço buscado. Na sequência, observa-se maior busca para o acolhimento entre os auxiliares administrativos (67 ou 8,7\%) teleatendimentos, recepcionistas (62 ou 8,0\%), e enfermeiros (51ou 6,6\%). Recepcionistas constituem a terceira categoria a procurar atenção psicológica com $15(4,6 \%)$ atendimentos no período. Familiares de trabalhadores que foram a óbito também têm sido atendidos no centro, entre outros casos que demandem atenção.

\section{Ações e estratégias necessárias para a promoção e proteção da saúde dos trabalhadores de saúde no contexto da pandemia}

Diante dessa situação, tratamos de revisar propostas, e sugestões contidas nos estudos e nos documentos visitados, buscando sistematizar recomendações aos gestores das instituições e serviços de saúde, especialmente os que lidam diariamente com a organização e gestão do trabalho dos profissionais e trabalhadores de saúde que estão na linha de frente do combate à pandemia.

Os estudos que tratam do controle da infecção por COVID-19 em profissionais de saúde que atuam no enfrentamento da pandemia reforçam a importância de medidas preventivas para a redução do risco de infecção entre os trabalhadores que atuam tanto ao nível hospitalar quanto na atenção primária, destacando-se a importância da lavagem de mãos, uso de EPIs - gorro, máscaras N95, luvas internas, óculos de proteção, roupas de proteção, capas para sapatos impermeáveis descartáveis, aventais de isolamento descartáveis, luvas externas e escudo facial -, por esses 
profissionais. Além disso, enfatiza-se os cuidados individuais com os profissionais de saúde, que incluem o controle de sintomas como febre, tosse, e realização de exames rotineiros - hemograma, tomografia torácica e autoexame de sintomas respiratórios e temperatura corporal - como forma de triagem desses profissionais.

Vários estudos destacam a necessidade de desinfecção da enfermaria a todo momento e gerenciamento de exposição ocupacional, via observação, em tempo real, com correção instantânea de algum procedimento faltante ou inadequado. Transformações na ambiência também são enfatizadas, como a inclusão de medidas rotineiras diárias como limpeza das máquinas anestésicas e respiradores, purificadores de ar para as áreas designadas, colocação e retirada de EPI, cobertura dos equipamentos médicos com papel filme, instruções para a inserção e retirada das roupas, restrição da área de circulação e até procedimentos no paciente que envolveriam a intervenção e a recuperação, no mesmo local. Além disso, sugerem a substituição de todos os documentos de papel por informações digitais, incluindo prescrições, fichas, registros médicos, informações de consentimento e resultados dos exames para evitar a troca de materiais entre os profissionais.

No que se refere à reorganização do processo de trabalho, destaca-se a adoção de turnos de 6 horas de trabalho dos enfermeiros, com superposição de uma hora e a implantação da monitoria on-line ou presencial do trabalho desses profissionais e a necessidade de separação de equipes em cuidadores e não cuidadores de COVID-19, para reduzir risco de transmissão, destacando-se, também, a necessidade de capacitação dos profissionais para a homogeneização dos processos de trabalho das equipes de saúde, enfatizando-se, inclusive, o uso de tecnologias digitais, como, por exemplo, o envio de vídeo sobre colocação e retirada de EPIs.

Vale ressaltar a criação de redes colaborativas voltadas à disponibilização de suporte técnico à capacitação de pessoal 
por meio de material instrucional - folhetos e brochuras -, workshops, disseminação de diretrizes, compartilhamento regular de atualizações técnicas, desenvolvimento de estudos de caso como estratégia pedagógica para capacitar os profissionais.

No que concerne à saúde mental dos profissionais de saúde, vários artigos descrevem ações de promoção e proteção da saúde mental dos profissionais de saúde e apontam a necessidade de se abordar melhor essa área, destacando-se a criação de equipes de suporte psicológicos aos profissionais de saúde, oferecimento de cursos on-line e outras estratégias que incluem micropráticas realizadas nos serviços hospitalares. (FESSELL; CHERNISS, 2020)

Em Nova York, por exemplo, estabeleceu-se uma força-tarefa de apoio para produzir respostas aos problemas de saúde mental advindos da COVID-19. Essa força-tarefa, composta por líderes de suporte de todo o Mount Sinai Health System (MSHS) - maior sistema hospitalar da cidade - realizou uma rápida avaliação de necessidades para capturar as preocupações da equipe e identificou três áreas prioritárias para promoção e manutenção do bem-estar de toda a força de trabalho do MSHS durante a pandemia, sendo elas: atender às necessidades básicas da força de trabalho durante a crise; aprimorar as comunicações para ajudar no fornecimento de mensagens atuais, confiáveis e tranquilizadoras que informam a força de trabalho; e desenvolver um conjunto robusto de opções de apoio psicossocial e de saúde mental facilmente acessíveis. (RIPP; PECCORALO; CHARNEY, 2020)

No caso brasileiro, o cuidado em saúde mental dos profissionais de saúde ainda está sendo estruturado através das secretarias municipais e estaduais da saúde com apoio das universidades públicas e centros de pesquisa que têm fornecido subsídios teóricos com base em evidências científicas produzidas em outros países. Nessa perspectiva, vem sendo propostos planos de contingência para atenção psicossocial e promoção da saúde mental dos 
trabalhadores da saúde em vários estados, assim como observa-se iniciativas de associações profissionais da área de saúde mental.

As ações desenvolvidas incluem o acolhimento e atendimento à crise, com intervenção psicossocial rápida, mas também a garantia de um conjunto de ações de caráter preventivo, no sentido de diminuir as probabilidades de os profissionais sofrerem danos psicossociais a médio prazo e especialmente ações que promovam ambientes protegidos e favoráveis à saúde mental dos trabalhadores da saúde. (DONG; BOUEY, 2020) Como estratégia de suporte aos trabalhadores que se encontram na linha de frente, vêm sendo propostas ações de PCPs por meio de serviços de suporte psicológico presenciais ou on-line para uma primeira escuta das necessidades de atenção psicológicas.

Grande parte dos cuidados de saúde mental necessários pode ser fornecida por meio de serviços de telemedicina, incluindo vídeo com profissionais de saúde mental, aplicativos móveis, recursos on-line e suporte virtual por pares. Tais serviços requerem o treinamento de psicólogos, psiquiatras e demais profissionais para atendimento, assim como a disponibilização de infraestrutura com telefones e dispositivos para interação. A rede de atenção psicossocial também poderá ser utilizada para atender a situações de crise seja da população, familiares e acompanhantes, como dos profissionais de saúde.

Como síntese, na organização das respostas e atenção em saúde mental aos profissionais de saúde no Brasil, no contexto pandêmico, pode-se caracterizar as ações considerando a natureza das práticas e a necessidade de se buscar a integralidade do cuidado conforme apresentado no Quadro 1. 
Quadro1 - Organização das respostas e da atenção em saúde mental aos profissionais de saúde no Brasil, no contexto da pandemia da COVID-19

\begin{tabular}{|c|c|}
\hline Ações de promoção da saúde & $\begin{array}{l}\text { Ambientes protegidos e favoráveis à saúde mental } \\
\text { dos trabalhadores da saúde; Reforço das capacidades } \\
\text { individuais e coletivas para manejo de situação de } \\
\text { estrese no trabalho e aumento da sobrecarga; }\end{array}$ \\
\hline Ações de prevenção da saúde & $\begin{array}{c}\text { Ações voltadas para diminuir as probabilidades } \\
\text { de os profissionais sofrerem danos psicossociais } \\
\text { a médio prazo; }\end{array}$ \\
\hline $\begin{array}{l}\text { Ações emergenciais de } \\
\text { acolhimento à crise }\end{array}$ & $\begin{array}{l}\text { Acolhimento e atendimento à crise, com intervenção } \\
\text { psicossocial rápida, em especial, aos trabalhadores } \\
\text { que se encontram na linha de frente; Primeiros Cuidados } \\
\text { Psicológicos (PCP) - logo após a ocorrência de evento } \\
\text { traumático, chamada de "debriefing psicológico"; } \\
\text { Suporte psicológico presencial ou on-line } \\
\text { para uma primeira escuta das necessidades } \\
\text { de atenção psicológicas; }\end{array}$ \\
\hline Atenção/apoio psicológico & $\begin{array}{l}\text { Serviços de telemedicina; Vídeo com profissionais } \\
\text { de saúde mental, aplicativos móveis, recursos on-line } \\
\text { e suporte virtual; A rede de atenção psicossocial também } \\
\text { poderá ser utilizada para atender a situações de crise; }\end{array}$ \\
\hline Atenção psiquiátrica & $\begin{array}{l}\text { Realizada por telemedicina ou consulta presencial } \\
\text { para casos de transtornos mentais instalados e que } \\
\text { requerem tratamento psicotrópico especializado. }\end{array}$ \\
\hline
\end{tabular}

Fonte: elaborado pelos autores.

\section{Comentários finais}

A análise detalhada das propostas e a sistematização do conjunto das recomendações aos gestores e profissionais de saúde, encontram-se, como referimos anteriormente, disponíveis no Boletim $\mathrm{n}^{\circ} 5$ da Rede Covida, entretanto, é necessário enfatizar, à guisa de conclusão, a importância de uma ampla divulgação, através da mídia e das redes sociais, do esforço que está sendo feito pelos profissionais e trabalhadores de saúde para conter o avanço, cuidar dos 
pacientes infectados e mitigar os efeitos da pandemia, mesmo nas condições precárias em que a maioria destes vêm trabalhando.

Consideramos importante, inclusive, que se desenvolvam estratégias de comunicação social que contribuam para a valorização do SUS e dos profissionais e trabalhadores que lutam cotidianamente para que esse sistema funcione, de modo que a população venha, a exemplo do que ocorre em países europeus que têm sistemas universais, a reconhecer a importância do SUS, coibindo atitudes e manifestações de hostilidade para com os profissionais de saúde.

Para concluir, então, cabe reiterar recomendação da OMS com relação ao apoio que a população em geral pode dar aos profissionais e trabalhadores em saúde. Para os profissionais de saúde que estão na linha de frente do combate à pandemia, um estímulo necessário é o reconhecimento do esforço, até mesmo do sacrifício que muitos estão fazendo para continuar trabalhando nas condições em que trabalham. Saber que a família está segura, e que os amigos e a sociedade valorizam seu trabalho é fundamental para que eles consigam enfrentar com coragem e esperança a difícil tarefa em que estão empenhados.

\section{Referências}

ALESSI, G. A luta contra o coronavírus tem o rosto de mulheres. El País, São Paulo, 2 maio 2020. Disponível em: https://brasil.elpais.com/brasil/2020-05-02/a-lutacontra-o-coronavirus-tem-o-rosto-de-mulheres.html. Acesso em: 13 ago. 2020.

ANELLI, F. et al. Italian doctors call for protecting healthcare workers and boosting community surveillance during covid-19 outbreak. BMJ, London, n. 368, p. m1254. 2020. Disponível em: https://www.bmj.com/content/368/bmj.m1254. Acesso em: 13 jun. 2020.

AYANIAN, J. Z. Mental Health Needs of Health Care Workers Providing Frontline COVID-19 Care. JAMA, Chicago, 2020. Disponível em: https://jamanetwork.com/ channels/health-forum/fullarticle/2764228. Acesso em: 1 maio 2020. 
BARSOUM, Z. Coronavirus (COVID-19) Pandemic and Health Workers of an Ethnic Group-A Slant on a Shocking Report. SN Comprehensive Clinical Medicine, Switzerland, 2020.

BHAUMIK, S. et al. Community health workers for pandemic response: a rapid evidence synthesis. BMJ Global Health, London, v. 5, n. 6, 2020.

BOLETIM EPIDEMIOLÓGICO COVID-19. Salvador: Secretaria de Saúde do Estado da Bahia, n. 129, 31 jul. 2020a. Disponível em: http://www.saude.ba.gov.br/ wp-content/uploads/2020/07/BOLETIM_ELETRONICO_BAHIAN_129_31072020. pdf. Acesso em: 13 ago. 2020.

BOLETIM EPIDEMIOLÓGICO COVID-19. Salvador: Secretaria de Saúde do Estado da Bahia, n. 45, 9 maio 2020b. Disponível em: http://www.saude.ba.gov.br/ wp-content/uploads/2020/05/BOLETIM_ELETRONICO_BAHIA_N_45_09_05_2020. pdf. Acesso em: 13 ago. 2020.

BOLETIM INFORMATIVO COVID-19: trabalhadores da Saúde. Salvador: Secretaria de Saúde do Estado da Bahia, n. 11, 17 jul. 2020c. Disponível em: http://www.saude.ba.gov.br/wp-content/uploads/2020/07/11\%C2\%BABOLETIM-INFORMATIVO-COVID-19-TRABALHADORES-DA-SA\%C3\%9ADE.pdf. Acesso em: 13 ago. 2020.

BOLETIM EPIDEMIOLÓGICO ESPECIAL: Doença pelo Coronavírus COVID-19. Brasília, DF: Ministério da Saúde Secretaria de Vigilância em Saúde, n. 21, 2020a. Disponível em: https://antigo.saude.gov.br/images/pdf/2020/July/08/Boletimepidemiologico-COVID-21-corrigido-13h35--002-.pdf. Acesso em: 13 ago. 2020.

BOLETIM EPIDEMIOLÓGICO ESPECIAL: Doença pelo Coronavírus COVID-19. Brasília, DF: Ministério da Saúde Secretaria de Vigilância em Saúde, n. 22, 2020 b. Disponível em: https://antigo.saude.gov.br/images/pdf/2020/July/15/Boletimepidemiologico-COVID-22.pdf. Acesso em: 13 ago. 2020.

BOLETIM EPIDEMIOLÓGICO ESPECIAL: Doença pelo Coronavírus COVID-19. Brasília, DF: Ministério da Saúde Secretaria de Vigilância em Saúde, n. 23, 2020c. Disponível em: https://antigo.saude.gov.br/images/pdf/2020/July/22/Boletimepidemiologico-COVID-23-final.pdf. Acesso em: 13 ago. 2020.

BOLETIM EPIDEMIOLÓGICO ESPECIAL: Doença pelo Coronavírus COVID-19. Brasília, DF: Ministério da Saúde Secretaria de Vigilância em Saúde, n. 24, 2020d. Disponível em: https://antigo.saude.gov.br/images/pdf/2020/July/30/Boletimepidemiologico-COVID-24.pdf. Acesso em: 13 ago. 2020. 
BOLETIM EPIDEMIOLÓGICO ESPECIAL: Doença pelo Coronavírus COVID-19. Brasília, DF: Ministério da Saúde Secretaria de Vigilância em Saúde, n. 25, 2020e. Disponível em: https://antigo.saude.gov.br/images/pdf/2020/August/12/Boletimepidemiologico-COVID-25-final--1-.pdf. Acesso em: 13 ago. 2020.

BOLETIM EPIDEMIOLÓGICO ESPECIAL: Doença pelo Coronavírus COVID-19. Brasília, DF: Ministério da Saúde Secretaria de Vigilância em Saúde, n. 26, $2020 f$. Disponível em: https://antigo.saude.gov.br/images/pdf/2020/August/12/Boletimepidemiologico-COVID-26.pdf. Acesso em: 13 ago. 2020.

BOLETIM EPIDEMIOLÓGICO ESPECIAL: Doença pelo Coronavírus COVID-19. Brasília, DF: Ministério da Saúde Secretaria de Vigilância em Saúde, n. 27, 2020g. Disponível em: https://antigo.saude.gov.br/images/pdf/2020/August/19/Boletimepidemiologico-COVID-27.pdf. Acesso em: 13 ago. 2020.

BOLETIM EPIDEMIOLÓGICO ESPECIAL: Doença pelo Coronavírus COVID-19. Brasília, DF: Ministério da Saúde Secretaria de Vigilância em Saúde, n. 28, 2020 h. Disponível em: https://antigo.saude.gov.br/images/pdf/2020/August/27/Boletimepidemiologico-COVID-28-FINAL-COE.pdf. Acesso em: 13 ago. 2020.

BOLETIM EPIDEMIOLÓGICO ESPECIAL: Doença pelo Coronavírus COVID-19. Brasília, DF: Ministério da Saúde Secretaria de Vigilância em Saúde, n. 29, 2020 i. Disponível em: https://antigo.saude.gov.br/images/pdf/2020/September/02/18hBoletim-epidemiologico-COVID-29-final.pdf. Acesso em: 13 ago. 2020.

BOLETIM EPIDEMIOLÓGICO ESPECIAL: Doença pelo Coronavírus COVID-19. Brasília, DF: Ministério da Saúde Secretaria de Vigilância em Saúde, n. 30, 2020j. Disponível em: https://antigo.saude.gov.br/images/pdf/2020/September/09/ Boletim-epidemiologico-COVID-30.pdf. Acesso em: 13 ago. 2020.

BIROLI, F. Divisão sexual do trabalho e democracia. Dados, Rio de Janeiro, v. 59, n. 3, p. 719-754, 2016. Disponível em: http://www.scielo.br/scielo. php?script=sci_arttext\&pid=S0011-52582016000300719\&lng=en\&nrm=iso. Acesso em: 5 maio 2020.

CHUGHTAI, A. A. et al. Policies on the use of respiratory protection for hospital health workers to protect from coronavirus disease (COVID-19). International Journal of Nursing Studies, Oxford, v. 105, p. 103567, May 2020. DOI: 10.1016/ j.ijnurstu.2020.103567. Disponível em: https://www.ncbi.nlm.nih.gov/pmc/articles/ PMC7174826/. Acesso em: 13 maio 2020. 
CONSELHO FEDERAL DE ENFERMAGEM (Brasil) - COFEN. Observatório de Emfermagem. Profissionais infectados com COVID-19 informado pelo serviço de saúde. Brasília, DF, 9 ago. 2020. Disponível em: http://observatoriodaenfermagem. cofen.gov.br/. Acesso em: 13 ago. 2020.

DONG, L.; BOUEY, J. Public Mental Health Crisis during COVID-19 Pandemic, China. Emerging Infectious Diseases, Atlanta, v. 26, n. 7, p. 1616-1618, 2020.

FESSELL, D.; CHERNISS, C. Coronavirus Disease 2019 (COVID-19) and Beyond: Micro-practices for Burnout Prevention and Emotional Wellness. Journal of the American College of Radiology, New York, v. 17, n. 6, p. 746-748, Jun. 2020.

FUNDAÇÃO OSWALDO CRUZ - FIOCRUZ. Saúde mental e atenção psicossocial na pandemia Covid: recomendações para gestores. Rio de Janeiro: Fiocruz: Ministério da Saúde, 2020. Disponível em: http://www.fiocruzbrasilia.fiocruz.br/ wp-content/uploads/2020/04/Sa\%C3\%BAde-Mental. Acesso em: 7 maio 2020.

HIRATA, H. Globalização, Trabalho e gênero. Revista de Políticas Públicas, São Luís, v. 9, n. 1, p. 111-1128, jul./dez. 2005. Disponível em: http://www. periodicoseletronicos.ufma.br/index.php/rppublica/article/view/3770. Acesso em: 30 maio 2020.

HANKIVSKY, O. Beyond sex and gender analysis: an intersectional view of the COVID-19 pandemic outbreak and response. Parkville, VIC, 31 Mar. 2020. Disponível em: https://mspgh.unimelb.edu.au/news-and-events/beyond-sex-andgender-analysis-an-intersectional-view-of-the-covid-19-pandemic-outbreak-andresponse. Acesso em: 28 maio 2020.

HUANG, L. et al. Special attention to nurses' protection during the COVID-19 epidemic. Critical Care, London, v. 24, n. 1, p. 120, Mar. 2020. DOI: 10.1186/ s13054-020-2841-7. Disponível em: https://ccforum.biomedcentral.com/ articles/10.1186/s13054-020-2841-7. Acesso em: 13 ago. 2020.

$\mathrm{KOH}, \mathrm{D}$. Occupational risks for COVID-19 infection. Occupational Medicine, London, v. 70, n. 1, p. 3-5, mar. 2020. DOI: 10.1093/occmed/kqaa036.

Disponível em: Acesso em: 13 ago. 2020.

LU, W. et al. Psychological status of medical workforce during the COVID-19 pandemic: A cross-sectional study. Psychiatry Research, Limerick, n. 288, p. 112936, June 2020.

LU, W. et al. Psychological status of medical workforce during the COVID-19 pandemic: A cross-sectional study. Psychiatry Research, Amsterdam, 2020. 
MACHADO, M. H.; XIMENES NETO, F. R. Gestão da educação e do trabalho em saúde no SUS: trinta anos de avanços e desafios. Ciências e Saúde Coletiva, Rio de Janeiro, v. 23, n. 6, p. 1971-1979, jun. 2018. DOI: http://dx.doi. org/10.1590/1413-81232018236.06682018. Disponível em: https://www.scielo.br/ scielo.php?script=sci_abstract \&pid=S1413-81232018000601971\&lng=pt\&nrm=iso. Acesso em: 18 maio 2020.

NIENHAUS, A; HOD, R. COVID-19 among Health Workers in Germany and Malaysia. International Journal Of Environmental Research and Public Health, Switzerland, v. 17, n. 13, p. 4881, 2020.

ORGANIZAÇÃO MUNDIAL DE SAÚDE -OMS; ORGANIZAÇÃO PAN-AMERICANA DE SAÚDE - OPAS. Folha Informativa - COVID 19. 2020. Disponível em: https://www.paho.org/bra/index.php?option=com content\&view=article\&id=6101: covid19\&ltemid=875. Acesso em: 5 maio 2020.

ORTIZ, Z. et al. Concerns and demands regarding COVID-19: Survey of health personnel, Medicina, [S. I.], v. 80, p. 16-24, 2020.

PESSA,V. E. et al. COVID-19 among health workers in Brazil: The silent wave. Journal of Global Health, Edinburgh, v. 10, n. 1, 2020.

PINTO, I. C. M.; PADILLA, M.; NUNES, T. C. M. Trabalho e educação em saúde: desafios para a garantia do direito à saúde e acesso universal às ações e serviços no Sistema Único de Saúde. In: ORGANIZAÇÃO PAN-AMERICANA DA SAÚDE. Relatório 30 anos de SUS, que SUS para 2030? Brasília, DF: OPAS, 2018. p. 139-158.

RAN, L. et al. Factors of Healthcare Workers with Corona Virus Disease 2019: A Retrospective Cohort Study in a Designated Hospital of Wuhan in China. Clinical Infectious Diseases, Chicago, Mar. 2020. DOI: 10.1093/cid/ciaa287. Disponível em: https://doi.org/10.1093/cid/ciaa287. Acesso em: 13 ago. 2020.

RIPP, J.; PECCORALO, L.; CHARNEY, D. Attending to the Emotional Well-Being of the Health Care Workforce in a New York City Health System During the COVID-19 Pandemic. Academic Medicine, Philadelphia, v. 95, n. 8, p. 1136-1139, 2020.

DOI: 10.1097/ACM.0000000000003414. Disponível em: https://journals.Iww.com/ academicmedicine/Fulltext/2020/08000/Attending_to_the_Emotional_Well_Being_ of_the.22.aspx. Acesso em: 13 ago. 2020.

TANNE, J. H. et al. COVID-19: how doctors and healthcare systems are tackling coronavirus worldwide. BMJ, London, n. 368, 2020. 
TEIXEIRA, C. F. de S.; PAIM, J. S. A crise mundial de 2008 e o golpe do capital na política de saúde no Brasil. Saúde em Debate, Rio de Janeiro, v. 42, n. 2 , p. 11-21, Oct. 2018. Disponível em: https://doi.org/10.1590/0103-11042018s201. Acesso em: 20 maio 2020.

TEIXEIRA, C. F. et al. A saúde dos profissionais de saúde no enfrentamento da pandemia de covid-19. Ciência e Saúde Coletiva, Rio de Janeiro v. 25 n. 9 , set. 2020.

WANG, J, ZHOU, M, LIU, F. Exploring the reasons for healthcare workers infected with novel coronavirus disease 2019 (COVID-19) in China. The Journal of Hospital Infection, London, v. 105, n. 1, p. 100-101, Mar. 2020. DOI: 10.1016/j. jhin.2020.03.002. Disponível em: https://www.journalofhospitalinfection.com/ article/S0195-6701(20)30101-8/fulltext. Acesso em: 26 jun. 2020.

(THE) WORLD economy will suffer from "long covid" too. The Economist, [s. I.], 13 Oct. 2020. Disponível em: https://www.economist.com/graphicdetail/2020/10/13/the-world-economy-will-suffer-from-long-covid-too. Acesso em: 13 ago. 2020.

YAN, $Y$ et al. Consensus of Chinese experts on protection of skin and mucous membrane barrier for healthcare workers fighting against coronavirus disease 2019. Dermatologic Therapy, Copenhagen, n. 33, p. 4, p. e13310, Mar. 2020. DOI: 10.1111/dth.13310. Disponível em: https://pubmed.ncbi.nlm.nih. gov/32170800/. Acesso em: 22 jul. 2020.

ZHANG, W. R. et al. Mental Health and Psychosocial Problems of Medical Health Workers during the COVID-19 Epidemic in China. Psychother Psychosom. Psychother Psychosom, Basel, v. 89, p. 4, p. 242-250, 2020. 